\title{
Mobility and language change
}

\author{
MALENE MONKA
}

In this article I present the result of my PhD study, which is the first real time panel-study made of the interrelationship between dialect change and mobility. The informants in the study are from three municipalities situated in different Danish dialect areas: Odder in Central Jutland, Vinderup in Western Jutland and Tinglev in Southern Jutland. The first interviews (1978-1989) were recorded as part of studies conducted at Copenhagen University and the Department of Border Region Studies. The informants were re-interviewed between 2005 and 2010 by researchers from the LANCHART Center and researchers at the University of Southern Denmark.

In the article the language change of six informants who have been geographically and socially mobile between the two recordings is compared to that of 17 geographically non-mobile informants. I present quantitative and qualitative analyses of the data. The two main quantitative findings are that the mobile speakers use fewer local features than the non-mobile speakers even before they are mobile, and that the degree of language change differs among the mobile informants from the three dialect areas. Based on the qualitative analyses I argue that differences in geographic and social orientation - i.e. mental mobility - can help explain differences between the language use of mobile and non-mobile informants. Following theories of place from human geography, I also suggest that place effects can help explain the differences between the language change of both mobile and nonmobile informants. 